\title{
METHOD FOR REMOVING BROKEN PROXIMAL FEMORAL NAILS USING EXISTING SCREW HOLE
}

\author{
MÉTODO DE REMOÇÃO DE HASTE FEMORAL PROXIMAL QUEBRADA \\ USANDO OS ORIFÍCIOS DE PARAFUSOS EXISTENTES
}

\author{
Cho Hong Man ${ }^{1}$, Min Woong BaE ${ }^{1}$ \\ 1. Department of Orthopedic Surgery, Gwangju Veterans Hospital, Gwangju, Korea.
}

\begin{abstract}
The use of intramedullary nailing to treat proximal femoral fractures has increased in recent years. Nail breakage is a rare complication of intramedullary nailing of the femur, and generally occurs at the non-united fracture site. Removal of the distal fragment of a broken nail is a challenging problem. In this article, the authors describe the methods used to remove strongly fixed broken intramedullary nails. Level of Evidence IV; Case series.
\end{abstract}

Keywords: Femur. Hip fractures. Fracture fixation, intramedullary. Prosthesis failure.

\section{RESUMO}

O uso de hastes intramedulares para tratar fraturas proximais do fêmur aumentou nos últimos anos. A quebra da haste é uma complicação rara das hastes intramedulares do fêmur, que em geral ocorre no local de não união da fratura. A remoção do fragmento distal da haste quebrada é um problema desafiador. Neste artigo, os autores descrevem os métodos usados para remover hastes intramedulares quebradas e com forte fixação. Nível de Evidência IV; Série de casos.

Descritores: Fêmur. Fraturas do quadril. Fixação intramedular de fraturas. Falha de prótese.

Citation: Cho HM, Min W. Method for removing broken proximal femoral nails using existing screw hole. Acta Ortop Bras. [online]. 2018;26(1):72-4. Available from URL: http://www.scielo.br/aob.

\section{INTRODUCTION}

In cases of delayed union or non-union, use of intramedullary (IM) nailing to treat proximal femoral fracture can lead to fatigue fracture of the implant. Distal fragments of the broken nail are difficult to remove, which has prompted many researchers to investigate various extraction and remedial techniques, all of which involve the application of both specially designed extraction tools and supplementary locking screws..$^{1-8}$ In this report, the authors present a new technique utilized to extract the broken distal portion of the IM nail in cases of proximal femoral fracture where the distal portion of the broken nail was firmly fixed in the medullary canal, making removal difficult. The simplicity of this technique lies chiefly in the fact that it does not require any specially made extractor.

\section{TECHNIQUE}

Patient history

A 69-year-old woman with left subtrochanteric femur fracture resulting from a fall underwent internal fixation using a proximal femoral nail antirotation (PFNA) (diameter: 9 mm, length: $200 \mathrm{~mm}$ ) at another hospital. (Figure 1A) Three months postoperatively, breakage of the nail passing through the distal locking screw hole was observed, along with signs of injury. (Figure 1B) Because the fragment of the broken nail could not be completely removed, it was left in situ, and revision surgery was performed at the same hospital using a locking plate. (Figure 1C) Six weeks after the second surgery, the patient was admitted to our hospital due to pain at the site of the subtrochanteric fracture. Radiography showed non-union of the fracture, breakage of the proximal part of the plate, and the remaining distal nail fragment. (Figure 1D). The patient had had hypertension for 5 years, which was well-controlled with medication. Her other medical history was non-specific; preoperative laboratory results showed no infectious or autoimmune disease. After removal of the locking plate and remaining nail fragment, the femur was reconstructed using a new Synthes Expert Antegrade Femoral Nail (A2FN nail, Synthes, Oberdorf, Switzerland). (Figures $1 \mathrm{E}$ and F) The surgery lasted 125 minutes; $250 \mathrm{ml}$ of blood was lost during the procedure, and the patient received transfusion (2 units).

\section{Surgical technique}

The patient was placed supine on a fracture table, as for ordinary proximal femoral fracture surgery. Under general anesthesia, the broken plate and locking screws were removed though incisions (using pre-existing incisions whenever possible). In order to extract the remaining distal nail fragment, the second screw hole below the distal end of the broken nail was enlarged by burring its upper edge medially and its lower edge laterally with a reamer, (Figure 2A) and a bulb-tipped guidewire was inserted in a retrograde manner.

All authors declare no potential conflict of interest related to this article. 
Previous surgical testing with PFNA fixation showed that the tip of the guidewire employed was too large to extract when inserted in a retrograde direction. The guidewire was carefully chosen in reference to the medullary canal diameter to avoid adverse effects on the medullary canal. (Figure 2B) The proximal portion of the retrograde-inserted guidewire was held firmly with a pin vise, and several hammer blows were performed to remove the remaining distal nail fragment, but without success. The screw hole was further reamed upwards and downwards. (Figure 2C) The screw was tapped cautiously with a slotted hammer to prevent damage to the cortical bone, and transferred the broken nail fragment slightly toward the proximal end. The fragment was then extracted by pulling back the guidewire. (Figures 2D and E) The cortical bone remained undamaged during the extraction process. After fracture reduction with the bone clamp, (Figure 2F) the A2FN nail was inserted. However, because the fracture reduction was not stable, a circular-shaped wire and crimp system were also employed. (Figure 1E) Because the inserted retrograde bulb tip wire still remained, a bendable Schanz screw was employed as an external fixator. (Figure 3A) By bending the screw, its contours were adjusted to prevent any damage to the reamed cortical bone. It was then inserted through the reamed screw hole and advanced to the distal end of the nail, where its slightly concave end contacted the bulb-tipped guidewire. (Figure 3B)

\section{DISCUSSION}

An IM nail can break if the fractured proximal femur does not heal or if the fixation for the fracture is not stable, leading to delayed union or non-union. Removal of the distal fragment of a broken nail can be challenging. Various extraction techniques involving specially designed instruments such as hooks, screws, or guidewires have been introduced. ${ }^{1-8}$

In cases of broken nails that are not tightly fixed, insertion of a long extractor with a distal hook is a common strategy. ${ }^{1}$ A hook cannot be used, however, if the inside of the nail is narrow. Alternatively, Brewster et al. ${ }^{2}$ and Kim et al. ${ }^{3}$ have suggested insertion of one or two straight guidewires in addition to a hook or bulb-tipped guidewire, respectively. It is not easy to insert more than two guidelines into the narrow inside space of the nail; moreover, insertion of multiple guidewires might also pose a problem when the nail canal is narrow. Park et al. ${ }^{4}$ reported that a broken nail was easily extracted using a flexible guidewire with a grooved and bent tip. This method can be adopted primarily when no other tools are available which can be employed without concern for possible damage to the medullary canal. While the flexible guidewire has a grooved distal end, unless its distal end is firmly engaged it can slip off the nail. It also is not useful when the broken nail is stuck within the medullary canal.

Magu et al. ${ }^{5}$ reported successful removal of a broken nail by inserting a ball-tipped guidewire with a $7 \mathrm{~mm}$ washer loaded retrogradely into the medullary canal. However, such an insertion is difficult when the IM nail is short, due to the long distance from the knee joint, as described in their study. An additional concern is that this method entails the removal of more than $7 \mathrm{~mm}$ of cortical bone,

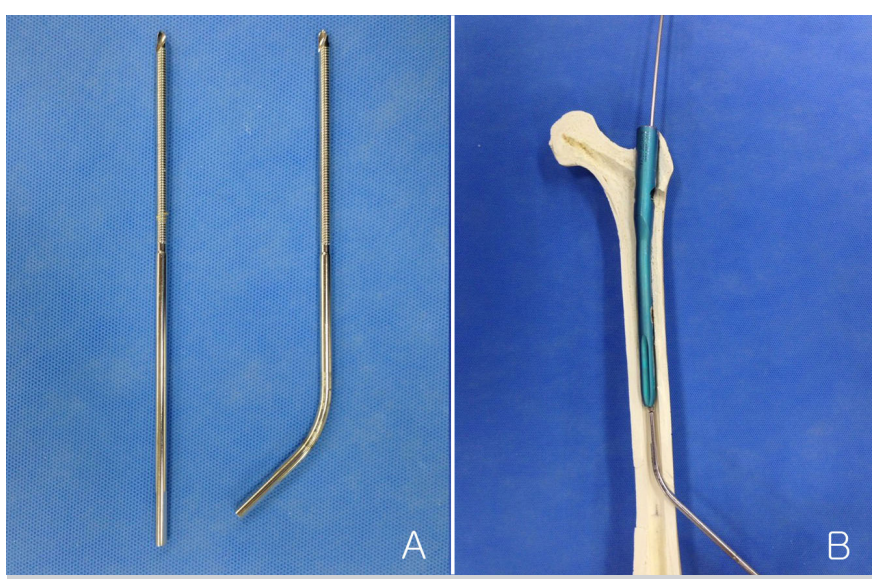

Figure 3. A) Schanz screw before and after bending. B) Bent Schanz screw and guide wire used to remove broken proximal femoral nail through screw hole.
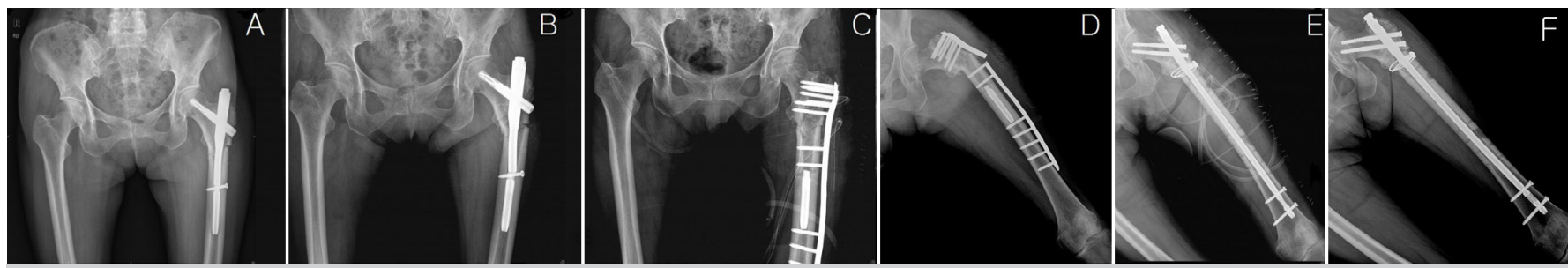

Figure 1. Subtrochanteric fracture in 69-year-old woman. A) Fixation using PFNA. B) Non-union and broken nail developed three months after initial operation. C) Second operation performed with locking plate. The broken distal nail tip remained after removal of the proximal portion of the PFNA. D) Non-union and hardware failure developed six weeks after second operation. E) Anteroposterior view of left femur after nailing. F) Radiograph at 6 months after surgery.
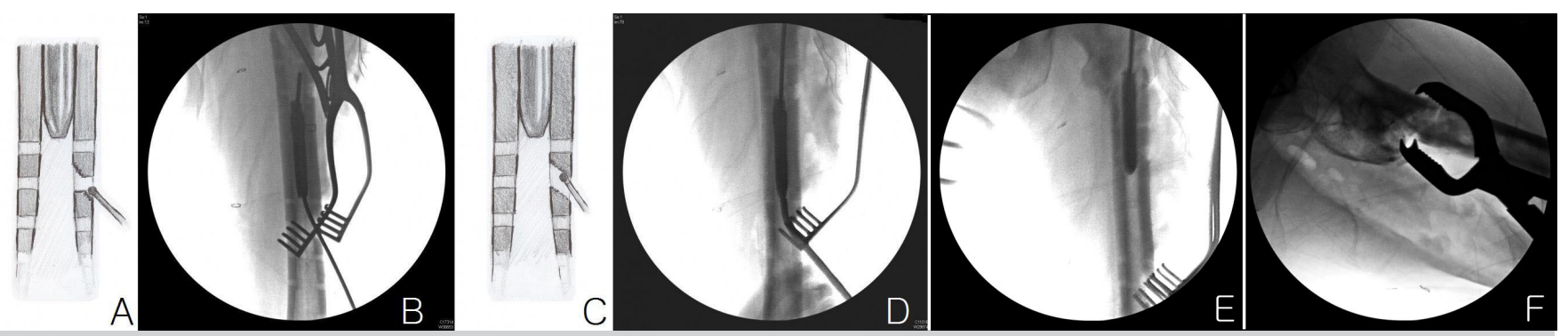

Figure 2. A) Small-sized burr used in reaming. B) Guidewire retrogradely delivered through distal end. C) Large-sized burr used in reaming. D) Schanz screw delivered through widened hole. E) Extraction of broken distal nail tip. F) Fracture reduction with bone clamp. 
with concomitant damage to the articular cartilage of the knee joint. Furthermore, a cortical bone defect below the implant increases the possibility of secondary injury resulting from accumulated fatigue in the bone. When the broken IM nail is only loosely fixed, a modified flexible guidewire has been successfully used for simple and easy removal. But this instrument, using the method described in this report, is difficult to use in cases of firmly fixed nails because of the lack of sufficient medullary space. Indeed, a nail firmly jammed at the isthmus of the medullary canal cannot be removed with such a guidewire. Alternatively, as reported of a previous study, ${ }^{6}$ a guidewire was inserted to the broken nail, after which a reamer was used to enlarge the space between the nail and the inner side of the cortical bone. Unfortunately, this method requires a special instrument, and is not suitable for small-diameter nails. Additionally, the reaming process can leave behind fragments that act as foreign bodies. Karladani et al. ${ }^{7}$ inserted a $3.5 \mathrm{~mm}$ screw, and Lee et al. ${ }^{8}$ a $10 \mathrm{~mm}$ k-wire insert, into the distal locking screw hole, and then pulled out the nail using the bulb-tipped guidewire. But because of the additional procedure, this method lengthens the surgical time and increases the intraoperative radiation load of the image intensifier. Furthermore, positioning the $10 \mathrm{~mm}$ wire accurately into the distal screw hole is not a simple procedure, because the wire can easily fall into the medullary canal, and removal is difficult. And even though the wire is fixed at the desired site, its function as an extracting instrument cannot be effective unless it is firmly connected with the ball-tipped guidewire.

\section{CONCLUSION}

Revision surgery performed to replace a broken proximal femoral nail usually requires a longer nail than that used in the initial surgery, as well as a distal locking screw hole made farther from the previous locking screw hole. In this present study on revision surgery, the authors instead utilized the pre-existing distal locking screw hole from a firmly fixed nail, reaming it slightly. If no distal screw hole was present, a new hole was formed for the removal. The reaming was performed cautiously, by burring the upper edge of the hole medially and the lower edge laterally, in order to minimize damage to the cortical bone.

AUTHORS' CONTRIBUTIONS: Each author made significant individual contributions to this manuscript. Cho HM (0000-0001-5160-2640)* and Min W (0000-0002-7500-7229)* were the main contributors in drafting the manuscript. Cho HM performed surgery, followed patients, and gathered clinical data. Min W performed the literature search, reviewed the manuscript, and contributed to the intellectual concept of the study. ${ }^{\star}$ ORCID (Open Researcher and Contributor ID)

\section{REFERENCES}

1. Poehling GG, Webb LX. Retrieval and replacement of a broken Küntscher rod by a closed technique. Technical note. J Bone Joint Surg Am. 1982;64(9):1389-90.

2. Brewster NT, Ashcroft GP, Scotland TR. Extraction of broken intramedullary nails--an improvement in technique. Injury. 1995;26(4):286.

3. Kim DS, Kwon CS, Ahn JK, Jeong BH, Sung YB, Yum JK, et al. Simple method for the extraction of the broken intramedullary nail of femur -case report. J Korean Orthop Assoc. 1999;34:171-4.

4. Park SY, Yang $\mathrm{KH}$, Yoo JH. Removal of a broken intramedullary nail with a narrow hollow. J Orthop Trauma. 2006;20(7):492-4.
5. Magu NK, Sharma AK, Singh R. Extraction of the broken intramedullary femoral nail-an innovative technique. Injury. 2004;35(12):1322-3.

6. Georgilas I, Mouzopoulos G, Neila C, Morakis E, Tzurbakis M. Removal of broken distal intramedullary nail with a simple method: a case report. Arch Orthop Trauma Surg. 2009;129(2):203-5.

7. Karladani $\mathrm{AH}$. Removal of a broken nail using a guide wire and a screw. Acta Orthop. 2006;77(6):986-8.

8. Lee $\mathrm{M}$, Yang $\mathrm{KH}$. Removal of a broken intramedullary nail with a narrow hollow using a bulb-tipped guide wire and kirschner wire: a case report. J Korean Fract Soc. 2010;23:377-81. 